\title{
ANNUAL ACTIVITY OF HANS GLACIER/SPITSBERGEN/ AS DETERMINED BY PHOTOGRAMMETRY AND MICRO-TREMORS \\ RECORDING
}

\author{
(Abstract) \\ by \\ J. Jania and L. Kolondra \\ (Department of Karst Geomorphology, Silesian University, ul. Mielczarskiego 60, 41-200 Sosnowiec, \\ Poland) \\ and S. Rudowski
}

(Institute of Geophysics, Polish Academy of Sciences, PkiN. Warszawa, Poland)

\section{ABSTRACT}

In the period from 1982 to 1984 , the Silesian University Expeditions investigated the annual cycle of the Hans Glacier velocity and front fluctuations. They also analysed the factors influencing these processes (J.Jania, L.Kolondra, E. Bukowska-Jania 1983).

Surrounding the Hans Glacier frontal zone, permanent tripods had been installed (by cementation in monolithic rocks) for the photo-theodolite, to establish three stereo-photogrammetric bases. While two of the three bases were used for surveying the fluctuations of the glacier front along the entire width (ca. $2.5 \mathrm{~km}$ ), the remaining one was installed to record the velocity of the glacier by the time-parallactic method. Photogrammetric pictures were reiterated approximately every 10 days during August in 1982, 1983 and 1984. During the polar winters of $1982 / 83$ and $1983 / 84$, the oscillations of the glacier front were recorded at one base only. Pictures were taken once a month (also by moonlight). Using a Gornik-type seismograph, natural micro-tremors coming from the glacier were recorded continually. The seismograph works at the nearby Polish Polar Station, which operates a meteorological station.

The application of permanent metal tripods with an auto-centering disc made it possible to take successive pictures at the same external orientation of the camera on one hand, while, on the other hand, improving the convergent photographs (a similar approach was reported by U. Voigt 1966). On the glacier surface, ground points of control were signalled with a Maltese cross. The investigators made use of natural reference points, i.e. some characteristic features of the glacier surface. Maximum errors of the photogrammetric survey were $\mathrm{m}_{\mathrm{xy}}= \pm 0.3 \mathrm{~m}$, $\mathrm{m}_{\mathrm{z}}= \pm 0.1 \mathrm{~m}$.

The results of glacier tongue velocity measurements (ca $\left.50 \mathrm{ma}^{-1}\right)$, as well as the results of measuring the fluctuations of the glacier front position enabled the rate of calving to be calculated. Thus, the calving velocity amounts to $\mathrm{ca} 100 \mathrm{ma}^{-1}$ and the mass loss at the contact with sea water approaches ca $20 \%$ of the annual mass loss due to ablation.

The calving speed and the velocity of the glacier undergo variations in different periods of the year and the maxima of the processes do not overlap. While the glacier velocity reaches its maximum value at the beginning of the summer season (July), maximum calving speed is recorded in autumn (September-October). However, there may appear a shift in the time at which these maxima occur. It depends on the meteorological conditions and the thermal state of the sea in the given year. The effect produced by the two "antagonistic" glacial processes is the change in position of the glacier front in the sea. Its maximum and minimum extension appears by the end of July and in October, respectively. The amplitude of the Hans Glacier front fluctuations, measured for the period of August, 1982 to August, 1983, amounted to $60 \mathrm{ma}^{-1}$ on the centre line. The results of photogrammetric surveying by $C$. Lipert, from 1957 to 1959, have shown that the maximum changes in the extension of the glacier front amount to $250 \mathrm{ma}^{-1}$ These fluctuations display regularities similar to those reported for the Columbia Glacier, Alaska by C.S. Brown, M.F. Meier and A. Post (1982).

Analyses of micro-tremors coming from the glacier involved their variability in scale and frequency from one day to the next and throughout the year, as well as photogrammetric survey. Attempts were also made to find the englacial source of those micro-tremors. Source location was attempted in the summer of 1980 , by using three geophones situated in the frontal part of the glacier. Thus, the majority of the micro-tremors owe their origin to the zone situated at a distance of 200 to $300 \mathrm{~m}$ from the front line and not to the ice cliff, as had been expected (A. Cichowicz, personal communication). It is worth noting that there exists an overlap of the annual distribution of the frequency of micro-tremor occurrence with the curve of glacier velocity variations. This enabled the investigator to determine the glacier dynamics by tremor recording. 